\title{
Elementary and Junior High School Teachers' Promotion of Self-Determination in Taiwan
}

\author{
Pen-Chiang $\mathrm{Chao}^{1} \& \mathrm{Yu}-\mathrm{Chi} \mathrm{Chou}^{1}$ \\ ${ }^{1}$ Department of Special Education, Chung Yuan Christian University, Taoyuan, Taiwan \\ Correspondence: Pen-Chiang Chao, Department of Special Education, Chung Yuan Christian University, Taiwan. \\ Taiwan. Tel: 886-3-265-6714. E-mail: chaopc@cycu.edu.tw
}

Received: April 4, 2017

doi:10.5539/ies.v10n9p141
Accepted: May 9, 2017 Online Published: August 27, 2017

URL: https://doi.org/10.5539/ies.v10n9p141

\begin{abstract}
The purpose of this study was to conduct a national survey, aiming to (a)explore how self-determination instruction is implemented by elementary and junior high school teachers; (b)examine the frequency with which the components of self-determination are taught; and (c)investigate whether teachers' gender, class setting, and teaching experience affect their classroom practices regarding the promotion of self-determination. The participants were 1,039 teachers recruited from elementary and junior high schools nationwide in Taiwan using a random sampling method. The Teaching Self-Determination Scale (TSDS) was used to gauge the extent to which educators teach knowledge and skills related to self-determination. Descriptive statistics, analyses of variance (ANOVAs) and multivariate analyses of variance (MANOVAs) were employed to analyze data collected. Findings showed that more than half of the teachers surveyed reported having often or always provided instruction to promote students' self-determination. The most frequently taught skills are related to Psychological Empowerment (self-advocacy skills, expecting positive outcomes), while the least frequently taught skills were primarily located in the domain of Self-Regulation (goal setting and problem solving skills). Furthermore, our findings showed that teachers' gender, class setting, and teaching experience were factors attecting the extent to which teachers delivered instruction to promote self-determination. Female teachers exhibited higher levels of implementation with respect to self-determination instruction. Teachers in general education classrooms showed significantly higher levels of applied self-determination instruction, followed by resource room teachers and self-contained classroom teachers. Additionally, teachers with more teaching experiences more frequently employed instructional activities promoting self-determination. Suggestions and implications are provided.
\end{abstract}

Keywords: self-determination, teachers, elementary school, junior high school

\section{Introduction}

The Special Education Act (SEA, 2014) of Taiwan was first enacted in 1973, and its seventh amendment was reauthorized in 2014 to further guarantee the quality of educational services provided to school-aged students with disabilities. During the past four decades, the SEA has provided school teachers with guidance as to how to tailor their instructional methods, lesson content, and assessments in accordance with students' physical and developmental needs. In addition to defining disability categories and determining eligibility for special education programs, the SEA also specifies principles that govern best practices relating to special education, including the promotion of students' self-awareness, self-advocacy, social inclusion and adaptation, positive contributions, and independence. These concepts are related to and essential for the notion of self-determination. Wehmeyer (1999) defined self-determination as a set of skills, including choice- and decision-making; problem solving; goal setting and attainment; self-awareness; self-advocacy and leadership; maintaining an internal locus of control; positive attributions of efficacy and expected outcomes; and self-knowledge. Research has shown that students with disabilities usually do not possess self-determination skills at the level required for academic success or to ensure a better quality of life (Carter, Lane, Pierson, \& Glaeser, 2006; Chambers et al., 2007). In addition, compared with typically developing peers, students with disabilities demonstrated lower levels of self-determination (Wagner, Newman, Cameto, Garza, \& Levine, 2005). Consequently, promoting the self-determination skills of students with disabilities has become one of the most important issues in the field of special education over the past two decades (Walker et al., 2011). There has been a general consensus that advanced self-determination is associated with positive educational outcomes, improved community living (Nota, 
Ferrari, Soresi, \& Wehmeyer, 2007), and better transition-related goals (Wehmeyer, Palmer, Soukup, Garner, \& Lawrence, 2007).

Even for students who initially lack self-determined behavior, research has indicated that skills and attitudes leading to self-determination can be developed through educational and instructional efforts (Agran, Cavin, Wehmeyer, \& Palmer, 2006; Kelly \& Shogren, 2014; Palmer \& Wehmeyer, 2003). In other words, self-determination skills are teachable. It is therefore particularly important to teach students related skills and attitudes in order to develop advanced self-determination. Given the importance of teaching skills related to self-determination, it is reasonable to investigate the ways in which teachers currently support students with disabilities in acquiring and developing these skills. The results of a national survey collected from more than one thousand middle and high school teachers of general and special education in the U.S. indicated that almost $60 \%$ of teachers teach skills to promote self-determination, including instruction in decision and choice making, problem solving, goal setting, self-awareness, and self-advocacy (Wehmeyer, Agran, \& Hughes, 2000). In addition, it also showed that teachers in less restrictive environments were more willing to make instructional efforts to promote self-determination. More specifically, general education teachers had the greatest tendency to teach self-determination skills, followed by resource room teachers, self-contained classroom teachers, and special school teachers. One implication of the study conducted by Wehmeyer et al. (2000) was that more than half of teachers would spend their instructional time on teaching students to become more self-determined. The other implication was that there was a correlation between the severity of students' disabilities and the intensity of teachers' instructional efforts, and that more research was needed to further investigate the causal relationship between these factors.

Another survey study by Carter, Lane, Pierson and Stang (2008) collected data from high school general and special education teachers, and found that teachers sometimes to often taught students skills and attitudes leading to advanced self-determination. As in the study conducted by Wehmeyer et al. (2000), the teachers' instructional focus included multiple components related to self-determination, such as self-knowledge, choice- and decision-making, self-advocacy, problem solving, and goal setting. Of these, problem solving was the most frequently taught skill, while self-advocacy was the least taught skill. Carter et al. (2008) surmised that the efforts to teach and provide more opportunities for high school students with disabilities to become more self-determined and to meet state and local achievement standards might be the result of standards-based reform, as well as the accountability system. The Individuals with Disabilities Education Act (IDEA, 2004), aligned with the No Child Left Behind Act (NCLB, 2002), reinforces the requirement of ensuring that students with disabilities have the opportunity to access and make progress within the general curriculum.

In contrast to the above-mentioned studies by Wehmeyer et al. (2000) and Carter et al. (2008), Thoma, Nathanson, Baker, and Tamura (2002) investigated only special education teachers (i.e., teacher working within either resource rooms or self-contained classrooms) from elementary to high school. Their results indicated that almost $80 \%$ of special education teachers teach students component elements of self-determined behavior, including choice- and decision-making, problem solving, goal setting, self-knowledge, and self-management skills. In rating the importance of each component skill, teachers prioritized choice- and decision-making, as well as problem solving; accordingly, these skills were most likely to be included in instruction. Additionally, Tung and Lin (2005) investigated special education teachers serving $10^{\text {th }}-12^{\text {th }}$ grade students with moderate to severe disabilities in special schools, and found that compared to their male colleagues, female teachers exhibited higher levels of implementation with respect to self-determination instruction.

To summarize the aforementioned literature, teachers of both general and special education, including (for the most part) both elementary and high school teachers, were willing to incorporate concepts and skills relating to self-determination into their regular instructional activities. In addition, the frequency with which skills related to self-determination were taught was greater than $50 \%$. However, for students with more severe disabilities, the frequency with which these skills were taught and the opportunities provided to practice these skills both decreased. In addition to students' personal factors, contextual factors relating to teachers' backgrounds were also critical to this result. Wehmeyer et al. (2000) indicated that teachers' reasons for not applying concepts relating to self-determination included a lack of familiarity with the theory of self-determination, as well as not viewing self-determination as a primary priority in educating students with more severe disabilities. In other words, the mediating factors affecting the delivery of instruction depended on teachers' knowledge of self-determination and their perception of the importance of promoting self-determination among students with disabilities. Similarly, in their survey of elementary school teachers, Cho, Wehmeyer, and Kingston (2013) found that teachers with a higher perception of the importance of self-determination were more likely to teach self-determination. Though the type of classroom setting (general education classroom, resource room, or 
self-contained classroom) did not affect general and special education teachers' perception of the importance of teaching self-determination, teaching experience was an effective predictor of teaching strategies related to self-determination. The results suggested that advanced teaching experience was positively associated with an increase in the frequency with which teachers taught self-regulation strategies, such as self-monitoring, self-evaluation, and goal-setting.

The above-mentioned self-determination literature has significant implications for special education practices in Taiwan as they relate to the promotion of self-determination among students with disabilities. The present study seeks to add to the understanding of general and special educators' implementation of self-determination instruction for students with disabilities. Currently, there are 69,280 students receiving special education and related services in elementary and junior high schools (two levels of compulsory education) in Taiwan. Of these, 48,620 students $(70.2 \%)$ were placed in resource rooms, 18,923 students $(27.3 \%)$ were placed in self-contained classrooms, and 1,737 (2.5\%) were placed in special schools. Students in resource rooms, depending on their individual learning needs, spend on average $25-50 \%$ of their time receiving remedial instruction in academic areas such as language arts (Chinese and English), math, social studies, and science. Our current educational policies align with inclusive practices, reinforcing the requirement of educating students with disabilities in the least restrictive environment (LRE). The LRE requirements are applicable to the $70 \%$ of students placed in resource rooms, and therefore both general and special education teachers are responsible for providing instruction to these students. In this sense, the level of self-determination attained by these students might be affected by the way in which educators perceive self-determination, and the frequency with which skills and strategies related to self-determination are taught. Due to the limited empirical evidence regarding practices relating to the promotion of self-determination in Taiwan, we so far have little understanding of how educators implement instruction relating to self-determination. Therefore, the purpose of the present study was to conduct a national survey, aiming to (a)explore how self-determination instruction is implemented by elementary and junior high school teachers; (b)examine the frequency with which the components of self-determination, such as self-awareness, psychological empowerment, self-regulation, and autonomy skills are taught; and (c)investigate whether teacher variables constitute factors (gender, class setting, and teaching experience) that affect educators' classroom practices regarding the promotion of self-determination.

\section{Method}

\subsection{Participants}

The participants in this study were 1,039 teachers recruited from 46 elementary schools and 32 junior high schools nationwide in Taiwan using a random sampling method. Among the participants, 555 were elementary educators, while the remaining 484 provided services at junior high schools. The majority of the teachers were female, while a plurality was between the ages of 31 and 40 . This reflects the national demographic features of educators working in the compulsory education phase (i.e. $1^{\text {st }}-9^{\text {th }}$ grades). Approximately $48 \%$ of the participants were general education teachers, while the others were special education teachers serving students with disabilities in resource rooms or self-contained classrooms. The participating educators were fairly experienced, in that $54.3 \%$ of the teachers surveyed had more than 11 years of work experience. The participants' demographics are presented in Table 1.

Table 1. Participant characteristics

\begin{tabular}{|c|c|c|c|c|c|c|}
\hline \multirow[t]{2}{*}{ Variable } & \multicolumn{2}{|c|}{$\begin{array}{l}\text { Elementary teachers } \\
\qquad(n=555)\end{array}$} & \multicolumn{2}{|c|}{$\begin{array}{c}\text { Junior high teachers } \\
\qquad(n=484)\end{array}$} & \multicolumn{2}{|c|}{ All teachers $(N=1,039$} \\
\hline & $n$ & $\%$ & $n$ & $\%$ & $N$ & $\%$ \\
\hline \multicolumn{7}{|l|}{ Gender } \\
\hline Male & 108 & 19.5 & 93 & 19.2 & 201 & 19.3 \\
\hline Female & 447 & 80.5 & 391 & 80.8 & 838 & 80.7 \\
\hline \multicolumn{7}{|l|}{ Age } \\
\hline 21 to 30 & 93 & 16.7 & 107 & 22.1 & 199 & 19.2 \\
\hline 31 to 40 & 243 & 43.7 & 233 & 48.1 & 476 & 45.8 \\
\hline 41 to 50 & 177 & 31.9 & 103 & 21.3 & 280 & 26.9 \\
\hline 51 and over & 43 & 7.7 & 41 & 8.5 & 84 & 8.1 \\
\hline \multicolumn{7}{|l|}{ Class Setting } \\
\hline Regular class & 273 & 49.2 & 228 & 47.1 & 501 & 48.2 \\
\hline Resource room & 155 & 27.9 & 134 & 27.7 & 289 & 27.8 \\
\hline
\end{tabular}




\begin{tabular}{|c|c|c|c|c|c|c|}
\hline Self-contained classoom & 127 & 22.9 & 122 & 25.2 & 249 & 24.0 \\
\hline \multicolumn{7}{|l|}{ Teaching Experience } \\
\hline Less than 5 years & 89 & 16.0 & 116 & 24.0 & 205 & 19.7 \\
\hline 6 to 10 years & 108 & 19.4 & 162 & 33.4 & 270 & 26.0 \\
\hline 11 to 15 years & 179 & 32.3 & 105 & 21.7 & 284 & 27.3 \\
\hline 16 years or more & 179 & 32.3 & 101 & 20.9 & 280 & 27.0 \\
\hline
\end{tabular}

\subsection{Measure}

This study uses the Teaching Self-Determination Scale (TSDS) proposed by Chao and Chou (2016). This measure is designed to gauge the extent to which elementary and junior high school educators teach knowledge and skills related to self-determination. The conceptual framework of the TSDS is based on a functional model of self-determination proposed by Wehmeyer (1999). It can be administered to both general and special education teachers. The 24-item scale is comprised of four subscales including Self-Realization (SR), Psychological Empowerment (PE), Self-Regulation (SG), and Autonomy (AT). Participants' responses are scored on a 5 -point Likert-type scale $(1=$ never, $2=$ rarely, $3=$ sometimes, $4=$ often, $5=$ always $)$. The overall composite score (Full Scale) for the TSDS ranges from 24 to 120. A higher score refers to a higher greater frequency of instruction in skills associated with self-determination. The SR subscale includes 5 items measuring the degree to which teachers provide instruction in self-observation, self-awareness, and self-knowledge (e.g., Teach students to identify personal strengths and weaknesses). The PE subscale consists of 6 items evaluating the extent to which teachers educate or empower students to have a positive belief regarding own ability, locus of control, and expectation of success (e.g., Encourage students to be hard-working people). The SG subscale includes 5 items assessing the extent to which teachers teach students goal setting and problem solving skills (e.g., Teach students how to plan a summer vacation). The AT subscale includes 8 items evaluating the extent to which teachers provide instruction in personal care, self-management, and independent living skills (e.g., Teach students how to keep personal hygiene). The reliabilities of the TSDS were established based on a total of 203 elementary and junior high school teachers who participated in a pilot study. The internal consistency coefficients (Cronbach's $\alpha$ ) for the subscales ranged from .76 to .88 ; the test-retest coefficients ranged from .78 to .85 . Full Scale's internal consistency and test-retest confficients were .93 and .89 , respectively. In addition, the construct validiy of the TSDS was assessed and found to be acceptable (Chao \& Chou, 2016). Specifically, the dimensionality of the TSDS was analyzed using exploratory factor analysis (EFA) with maximum likelihood estimation method. Based on the scree plot and the a priori hypothesis, four factors were rotated using the Varimax rotation procedure. The rotated solution yielded four interpretable factors (SR, PE, SG, and AT) accounting for $51.5 \%$ of the total item variance. Each item had the highest factor loading relative to its own subscale. Furthermore, a confirmatory factor analysis (CFA) was performed to evaluate the validity of the TSDS construct. Results showed that the model provided a good fit to the data, which supports the claim that the four-factor model adopted by the TSDS is appropriate. The fit indices, including absolute indices (GFI $=.967$, $\mathrm{AGFI}=.908, \mathrm{RMSEA}=.078)$ and relative indices $(\mathrm{NFI}=.970, \mathrm{RFI}=.935, \mathrm{IFI}=.983, \mathrm{TLI} / \mathrm{NNFI}=.963, \mathrm{CFI}$ $=.983$ ), were all adequate.

\subsection{Procedures}

Two research assistants who participated in a grant research project reviewed a list of public elementary and junior high schools nationwide in Taiwan and randomly selected from among those schools that have resource rooms and/or self-contained classrooms. The assistants then contacted the director of academic affairs at each of the chosen schools by phone and asked for permission to include their schools in the present study. Surveys and consent forms were then mailed to the directors who agreed to participate. The directors were asked to distribute the surveys to a pair of general and special education teachers who were matched according to their gender and the grade level of their students.

\subsection{Data Analysis}

Descriptive statistics were first computed for each of the four subscales and for the TSDS composite score (i.e., Full Scale). A series of one-way analyses of variance (ANOVAs) and multivariate analyses of variance (MANOVAs) were then employed to examine differences in TSDS scores among different groups, using teachers' gender, class setting, and teaching experience as independent variables. A significant MANOVA was followed by conducting follow-up univariate tests and post hoc comparisons. To control for Type I errors, the Bonferroni method and Holm's sequential Bonferroni procedure were used in the MANOVAs and ANOVAs, respectively. 


\section{Results}

\subsection{Frequency Analysis of the TSDS}

The overall descriptive statistics indicated that between approximately one third and one half $(35.4 \%-46.1 \%)$ of the teachers reported that they often delivered instruction to promote students' enhanced self-determination. This was the most frequently reported response for each of the four subcategories. The next most frequent responses were sometimes for Self-Realization, Self-Regulation, and Autonomy, and always for Psychological Empowerment. In general, more than $80 \%$ of the teachers reported that they sometimes to always provided instruction to promote students' self-determination; $20-30 \%$ reported sometimes; $50-80 \%$ reported often or always. Fewer than one-fifth of the respondents reported that they rarely or never provided instruction leading to enhanced self-determination. Table 2 summarizes the frequency with which each response was reported by the teachers surveyed.

Table 2. Teachers' overall ratings of the TSDS subscales

\begin{tabular}{lccccc}
\hline \multirow{2}{*}{ Subscale } & \multicolumn{3}{c}{ Percentage of Response (\%) } \\
\cline { 2 - 6 } & Never & Rarely & Sometimes & Often & Always \\
\hline Self-Realization & 1.3 & 6.2 & 30.2 & 46.1 & 16.2 \\
Psychological Empowerment & 1.3 & 3.9 & 18.8 & 45.1 & 30.9 \\
Self-Regulation & 2.1 & 9.3 & 29.1 & 41.5 & 18.0 \\
Autonomy & 4.0 & 13.7 & 30.8 & 35.4 & 16.1 \\
\hline
\end{tabular}

\subsection{Mean Analysis of the TSDS}

The teachers' average score measured on the TSDS's Full Scale was $89.40(S D=13.41)$, with the mean values for the four subscales ranging from 17.51 to 28.78 (see Table 3). For within-subject comparisons, due to the unequal number of items in each subscale, an item mean was obtained by dividing the subscale mean by the number of subscale items. Results of the repeated-measures ANOVA indicated a significant difference in means among the four subscales (Wilks' $\Lambda=.49, F(3,1036)=358.79, p<.001, \eta^{2}=.51$ ). Subsequent univariate analyses were tested with a paired-sample $t$ test and Holm's sequential Bonferroni method (for which $\alpha$ was set to values ranging from .008 to .05) in order to reduce Type I error rates. Table 3 summarizes the results, which indicate that the item mean scores for each subscale were significantly different from one another. The item mean score for Psychological Empowerment was found to be significantly greater than the item mean scores for each of the other three subscales; specifically, the t-statistics and p-values for the paired-sample t-tests show that the item mean score for Psychological Empowerment was greater than those of Self-Realization $(t(1038)=21.09$, $p<.001)$, Self-Regulation $(t(1038)=30.99, p<.001)$, and Autonomy $(t(1038)=24.41, p<.001)$. Similarly, the item mean score for Self-Realization was greater than those of Self-Regulation $(t(1038)=12.72, p<.01)$ and Autonomy $(t(1038)=6.52, p<.001)$. Finally, the item mean scores for Self-Regulation and Autonomy were also found to be significantly different from one another $(t(1038)=4.98, p<.01)$.

Table 3. Teachers' means, standard deviations, and item means

\begin{tabular}{lccc}
\hline Subscale & $M(S D)$ & Number of items & Item $M$ \\
\hline Self-Realization & $18.63(3.20)$ & 5 & 3.73 \\
Psychological Empowerment & $24.49(3.90)$ & 6 & 4.08 \\
Self-Regulation & $17.51(3.39)$ & 5 & 3.50 \\
Autonomy & $28.78(5.57)$ & 8 & 3.60 \\
\hline
\end{tabular}

\subsection{Most and Least Frequently Taught Skills}

Table 4 lists the most and least taught skills relating to self-determination, as represented by the top $25 \%$ and bottom $25 \%$ of responses on the TSDS. Of the six most frequently taught skills, five were located within the domain of Psychological Empowerment. It was also noted that teachers frequently taught problem-solving skills related to peer conflicts or arguments. By contrast, the least frequently taught skills were in the domains of Self-Regulation and Autonomy. Use of public transportation was the least taught skill, with an average score of less than 3.00 . 
Table 4. Teachers' most and least frequently taught skills

\begin{tabular}{|c|c|}
\hline Items & Subscale \\
\hline \multicolumn{2}{|l|}{ Most Frequently Taught Skills } \\
\hline Value his/her life $(M=4.21, S D=.80)$ & Psychological Empowerment (PE) \\
\hline Persevere regardless of past failures $(M=4.14, S D=.78)$ & $\mathrm{PE}$ \\
\hline $\begin{array}{l}\text { Understand the notion of no gains without pain }(M=4.10, S D \\
=.83)\end{array}$ & $\mathrm{PE}$ \\
\hline Be confident in themselves $(M=4.09, S D=.79)$ & PE \\
\hline Resolve arguments with classmates $(M=4.04, S D=.79)$ & Self-Regulation (SG) \\
\hline $\begin{array}{l}\text { Encourage students to be hard-working people }(M=4.02, S D \\
=.83)\end{array}$ & $\mathrm{PE}$ \\
\hline \multicolumn{2}{|l|}{ Least Frequently Taught Skills } \\
\hline Use public transportation $(M=2.85, S D=1.10)$ & Autonomy (AT) \\
\hline Plan a summer vacation $(M=3.14, S D=.97)$ & SG \\
\hline Engage in leisure activities $(M=3.32, S D=.93)$ & $\mathrm{AT}$ \\
\hline Set attainable career goals $(M=3.38, S D=.98)$ & SG \\
\hline Behave properly in various occasions $(M=3.51, S D=.92)$ & SG \\
\hline $\begin{array}{l}\text { Develop goal setting and attainment strategies }(M=3.53, S D \\
=.89)\end{array}$ & SG \\
\hline
\end{tabular}

\subsection{Comparisons among Groups on the TSDS Full Scale}

An ANOVA indicated a significant difference in the TSDS Full Scale results with respect to gender $(F(1,1037)$ $\left.=6.93, p=.009, \eta^{2}=.01\right)$; specifically, female teachers outscored male teachers. Using class setting as the independent variable, the ANOVA yielded a significant group difference on the TSDS Full Scale $(F(2,1036)=$ $10.11, p<.001, \eta^{2}=.02$ ). Follow-up tests applying Holm's sequential Bonferroni procedure to control for Type I errors showed that teachers who worked in regular classrooms outscored those who taught in either resource rooms $(p<.01)$ or self-contained classrooms $(p=.024)$.

The ANOVA evaluating the differences among teachers with varying years of teaching experience on the TSDS full scale (divided into four representative groups) yielded statistically significant results $(F(3,1035)=10.62, p$ $<.001, \eta^{2}=.03$ ). Using Holm's sequential Bonferroni procedure, follow-up tests indicated three significant pairwise comparisons. Teachers who had been teaching for 16 years or more outscored those with teaching experience of less than 5 years $(p=.001), 6-10$ years $(p=.001)$ and $11-15$ years $(p=.001)$.

\subsection{Comparisons among Groups on the TSDS Subscales}

Results of a one-way MANOVA showed a statistically significant gender difference on the four subscales of the TSDS (Wilks's $\left.\Lambda=.98, F(4,1034)=4.55, p=.001, \eta^{2}=.02\right)$. ANOVAs were then conducted on each of the subscales as follow-up tests. Each ANOVA was tested using the Bonferroni method at the .025 level (.05/2) in order to control for Type 1 errors across the two univariate ANOVAs. Results indicated that the ANOVAs were statistically significant for three of the four subscales: Self-Realization $\left(F(1,1037)=5.11, p=.024, \eta^{2}=.01\right)$, Psychological Empowerment $\left(F(1,1037)=10.17, p=.001, \eta^{2}=.01\right)$, and Autonomy $(F(1,1037)=6.46, p=.011$, $\left.\eta^{2}=.01\right)$. Female teachers outscored their male counterparts on all three subscales. The means and standard deviations corresponding to each of the four dependent variables obtained for male and female teachers are presented in Table 5.

The MANOVA yielded a significant group difference among the teachers from three different class settings on the four subscales of the TSDS (Wilks's $\Lambda=.74, F(8,2066)=41.11, p<.001, \eta^{2}=.142$ ). ANOVAs were then conducted on each subscale as follow-up tests. Each ANOVA was tested using the Bonferroni method at the .017 level $(.05 / 3)$ in order to control for Type I errors. The ANOVAs yielded significant results for each subscale: Self-Realization $\left(F(2,1036)=9.85, p<.001, \eta^{2}=.02\right)$, Psychological Empowerment $(F(2,1036)=24.68, p$ $\left.<.001, \eta^{2}=.05\right)$, Self-Regulation $\left(F(2,1036)=35.21, p<.001, \eta^{2}=.06\right)$, and Autonomy $(F(2,1036)=23.79, p$ $<.001, \eta^{2}=.05$ ). Post hoc analyses were then conducted for each subscale; these consisted of pairwise comparisons designed to assess the mean differences among the three class setting groups. Each pairwise comparison was tested using the Bonferroni method at the .006 level $(.017 / 3)$. In this analysis, general classroom teachers outscored resource room teachers $(p=.001)$ and self-contained classroom teachers $(p=.001)$ with respect to Self-Realization. General classroom teachers also outscored resource room teachers $(p<.001)$ and self-contained classroom teachers $(p<.001)$ with respect to Psychological Empowerment and Self-Regulation, 
while self-contained classroom teachers outscored general classroom teachers $(p<.001)$ and resource room teachers $(p<.001)$ with respect to Autonomy. Table 5 lists the means and standard deviations among the teachers form three different class settings on the four subscales.

Results of the MANOVA showed a significant difference on the four subscales of the TSDS among teachers with varied teaching experience (Wilks's $\Lambda=.95, F(12,2730)=4.43, p<.001, \eta^{2}=.02$ ). ANOVAs were then conducted on each subscale as follow-up tests. Each ANOVA was tested using the Bonferroni method at the .013 level (.05/4) in order to control for Type I errors across the four univariate ANOVAs. The ANOVAs yielded significant results for each subscale: Self-Realization $\left(F(3,1035)=3.64, p=.012, \eta^{2}=.01\right)$, Psychological Empowerment $\left(F(3,1035)=11.85, p<.001, \eta^{2}=.03\right)$, Self-Regulation $\left(F(3,1035)=5.39, p=.001, \eta^{2}=.02\right)$, and Autonomy $\left(F(3,1035)=9.98, p<.001, \eta^{2}=.03\right)$. Post hoc analyses were then conducted for each subscale. These consisted of pairwise comparisons designed to assess the mean differences among the four teaching experience groups. Each pairwise comparison was tested using the Bonferroni method at the .002 level (.013/6). Only the Psychological Empowerment and Autonomy subscales were found to yield significant results. With respect to Psychological Empowerment, teachers with 16 or more years of work experience consistently outscored those with fewer than 5 years $(p<.001), 6-10$ years $(p<.001)$, and $11-15$ years of experience $(p$ $<.001)$. Likewise, with respect to Autonomy, teachers with teaching experience of 16 years or more outscored those with less than 5 years $(p<.001)$ and 6-10 years $(p=.001)$. Furthermore, the 11-15 year group also outscored those teachers with fewer than 5 years' experience $(p=.001)$. Means and standard deviations among the teachers with varied teaching experience on the subscales are presented in Table 5.

Table 5. Means and standard deviations for the TSDS as a function of teacher gender, class setting, and teaching experience

\begin{tabular}{|c|c|c|c|c|c|c|}
\hline \multirow{3}{*}{ Variable } & \multirow{3}{*}{$n$} & \multicolumn{4}{|c|}{ Subscale } & \multirow{2}{*}{ Full Scale } \\
\hline & & Self-Realization & Psychological Empowerment & Self-Regulation & Autonomy & \\
\hline & & $M(S D)$ & $M(S D)$ & $M(S D)$ & $M](S D)$ & $M(S D)$ \\
\hline Male & 201 & $18.17(3.28)$ & $23.71(4.09)$ & $17.44(3.41)$ & $27.88(5.42)$ & $87.17(13.91)$ \\
\hline Female & 838 & $18.74(3.17)$ & $24.68(3.84)$ & $17.52(3.39)$ & $28.99(5.59)$ & $89.94(13.23)$ \\
\hline Regular class & 501 & $19.08(3.17)$ & $25.32(3.62)$ & $18.33(3.14)$ & $28.53(5.84)$ & $91.23(13.24)$ \\
\hline Resource room & 289 & $18.23(3.24)$ & $24.03(3.93)$ & $17.14(3.11)$ & $27.57(5.22)$ & $86.97(12.98)$ \\
\hline Self-contained class & 249 & $18.18(3.10)$ & $23.37(4.05)$ & $16.27(3.74)$ & $30.74(4.84)$ & $88.53(13.73)$ \\
\hline Less than 5 years & 205 & $18.38(2.88)$ & $23.82(3.79)$ & $16.99(3.33)$ & $27.38(5.76)$ & $86.57(12.28)$ \\
\hline 6 to 10 years & 270 & $18.60(3.19)$ & $24.17(3.80)$ & $17.37(3.19)$ & $28.41(5.42)$ & $88.55(12.95)$ \\
\hline 11 to 15 years & 284 & $18.33(3.16)$ & $24.15(4.10)$ & $17.37(3.29)$ & $28.86(5.48)$ & $88.71(13.67)$ \\
\hline 16 years or more & 280 & $19.14(3.42)$ & $25.64(3.65)$ & $18.16(3.64)$ & $30.07(5.37)$ & $92.99(13.68)$ \\
\hline
\end{tabular}

\section{Discussion}

Due to the increasing adoption of inclusive practices in Taiwan, a growing number of students with disabilities are being educated in mainstream classes and receiving remedial instruction in resource rooms where necessary. This means that general education teachers as well as special education teachers have an educational impact on students with disabilities, including their acquisition and development of self-determination skills. Prior research has shown that there exists a positive correlation between advanced self-determination skills and greater academic achievement (Gaumer-Erickson, Noonan, Zheng, \& Brussow, 2014; Konrad, Fowler, Walker, Test, \& Wood, 2007), as well as improved quality of life (Nota et al., 2007). The present study therefore presents a national survey of elementary and junior high school teachers in Taiwan (representing two levels of compulsory education), and investigates the extent to which these teachers currently provide students with disabilities with instruction in skills related to self-determination. The findings presented in this study will have implications for practitioners and other professionals who are engaged in curriculum planning and policy making.

The results of the present study indicate that more than $90 \%$ of the teachers surveyed reported having provided instruction to promote students' self-determination, and that fewer than 5\% reported having never provided instruction leading to enhanced self-determination. This suggests that teachers are complying with current principles and policies relating to special education practices in Taiwan. Despite some observed variation in the levels of implementation between subscale skills, the results were acceptable in that more than half of the Taiwanese teachers surveyed reported having often or always provided instruction to promote students' self-determination. On average, the literature shows that $60 \%$ (Wehmeyer et al., 2000) to $80 \%$ (Thoma et al., 
2002) of teachers would support instruction promoting self-determination for students with disabilities, and that self-determination instructional support is available sometimes to often (Carter et al., 2008). In spite of the high rate at which self-determination skills are taught, the concept of self-determination, being influenced by western theoretical frameworks and teaching models, is relatively new in Taiwan. This paradigm is therefore not strongly supported within family networks and in related services provided for students with disabilities. Another cultural and educational phenomenon that should not be overlooked is the teacher-dominated approach to teaching, which leaves limited opportunities for students to become self-directed learners. It would be a useful endeavor for future research to continue to investigate the ways in which teachers can support the acquisition and development of self-determination skills by students with disabilities in a culturally responsive way.

There are several additional findings of the present study that are worth discussing. First, the most frequently taught self-determination skills are related to Psychological Empowerment, including self-advocacy, developing an internal locus of control, and expecting positive outcomes. The next most frequently taught skills were those relating to Self-Realization, Autonomy, and Self-Regulation in descending order. These results differ from those of Thoma et al. (2002), whose findings indicated that decision-making, choice-making, and problem solving were the three most frequently taught skills among elementary and secondary teachers. In our study, instruction on decision- and choice-making was grouped in the Self-Realization category, while problem solving was categorized under Self-Regulation. We account for the difference in these findings as follows. First, only special education teachers were included in Thoma et al.'s (2002) study, while the present study includes both general and special education teachers. In addition, special education teachers tend to teach self-knowledge and decision-making skills based on students' own strengths, weakness, and interests as a first step in promoting the development of self-determination (Jones, 2006; Powers et al., 2001). This would explain the emphasis on decision- and choice-making among special education teachers reported by Thoma et al (2002). Secondly, from a cultural perspective, Taiwan's overly teacher-dominated and test-oriented learning environment might result in low confidence, scholastic failure, external loci of control, and/or negative outcome expectancy being noticed among students with and without disabilities. Thus, it would be reasonable for Taiwanese teachers to focus more on instruction related to abilities leading to enhanced psychological empowerment. Similarly, in the analyses of most and least frequently taught skills relating to self-determination, five out of six most frequently taught skills fell into the domain of Psychological Empowerment. These were instruction on: "value his/her life", "persevere regardless of past failures", "understand the notion of no gains without pain", "be confident in themselves", and "encourage students to be hard-working people". The last four of these skills are relevant in the context of achieving success in school.

Relatively speaking, the least frequently taught skills were primarily located in the domain of Self-Regulation. Though this does not necessarily imply that the instructional support in this area is insufficient, it is worth discussing the factors underlying this finding. First, we speculate that self-regulating behaviors are perceived to be less of a direct result of instructional teaching than other skills, and are therefore less likely to become a subject of focus in the classroom. Comprehensively planned instructional strategies are therefore required in order to systematically support students' goal-setting and attainment. For example, a study conducted by Burstein, Bryan, \& Chao (2005) employed a 10-step problem-solving strategy, where each step involved different levels of cognitive strategies and executive functioning skills. Second, based on our analysis of the most and least frequently taught skills relating to self-determination, the low frequency with which skills relating to self-regulation are taught might somewhat reflect teachers' perceptions that these skills are less important. Of the six least taught skills, four were in the domain of Self-Regulation, including skills such as planning a summer vacation, setting possible career goals, behaving properly in various situations, and developing goal setting and attainment strategies. Thirdly, Taiwanese cultural and social values might be factors contributing to a lower degree of encouragement for students in setting their own educational goals, or even goals for life in general. In fact, parents and teachers of students in Taiwan usually make well-intentioned decisions on their behalf instead. In most cases, parents and teachers expect their children or students to pass national exams or admission screenings in order to successfully enter high school or college after graduating from junior high school, even though higher education is not suitable for all students.

There are three additional skills to be discussed with regard to the level at which instruction in self-determination skills is implemented. Finding ways to resolve conflicts or arguments with peers was one of the six skills that were most frequently taught. Peer conflict resolution was categorized as falling within the domain of Self-Regulation, while the other five most-taught skills fell within the domain of Psychological Empowerment. Unlike other self-regulated behaviors and skills, which tended to be under-taught, teachers placed more focus on teaching students how to handle peer conflicts and arguments. It is evident that teachers invest significant effort 
into creating warm and interactive classrooms, leading to improved teaching efficacy and better learning performance. In terms of less frequently taught skills, instruction on teaching students how to use public transportation and engage in leisure activities, both of which fall within the domain of Autonomy, were the least and third-least taught, respectively. This might indicate that teachers view these skills as less important. We suspect that parents may be primarily responsible for transporting their children to and from their schools, and that in some districts public transportation may not be convenient and accessible for students with disabilities. Regarding leisure activities, from a cultural and traditional perspective, these may not occupy a central focus in our public education system to the same extent that they might in some western education systems. The goal of developing the ability to manage leisure activities is undermined by the emphasis on academic performance in the competitive Taiwanese learning environment. This is in part because the focus of instruction is dominated by what will be included in the national tests. Future research may discover additional factors affecting the degrees to which these self-determination skills are taught.

Regarding the personal factors affecting teachers' application of self-determination skills, the present study shows that teachers' gender, class settings, and teaching experience were factors that would affect the extent to which teachers delivered instruction to promote self-determination. Female teachers exhibited higher levels of implementation with respect to self-determination instruction. This result is consistent with the findings of the research conducted by Tung and Lin (2005), suggesting the correlation between teachers' gender and the level of self-determination instruction. We surmise that because female teachers are over-represented in primary (71\%) and secondary (69\%) schools in Taiwan, this dynamic within the teaching profession might affect our investigation of the role of gender differences on teacher self-efficacy in all forms of instruction, including self-determination instruction. As for class settings, the present study suggests that except for skills taught in the domain of Autonomy, teachers in general education classrooms showed significantly higher levels of applied self-determination instruction (as well as all other related skills), followed by resource room teachers and self-contained classroom teachers. These results are consistent with those of Wehmeyer et al. (2000), indicating that there exists a correlation between the levels at which self-determination instruction is implemented and the extent to which the educational setting applies the least restrictive environment (LRE) principle. Since cognitive functioning still remains the primary consideration in educational placement in Taiwan, it also to some degree supports other findings in the literature, which indicate that levels of instructional effort could be affected by the intellectual functioning of students and the severity of their disabilities (Carter, Lane, Pierson, \& Glaeser, 2006). As noted in the results of this study, self-contained classroom teachers of students with moderate to severe disabilities demonstrated greater instructional efforts in teaching behaviors and skills related to Autonomy. This finding indicates the importance of a functional curriculum as a central instructional focus in educating students with severe and multiple disabilities, and of emphasizing self-management skills, community living skills, career preparation to promote autonomy and independency. In addition, teachers with more teaching experiences more frequently employed instructional activities promoting self-determination. This result is consistent with the findings of Cho et al. (2013), suggesting that there exists a positive correlation between teaching experience and the practice of self-determination instruction.

In conclusion, the present study demonstrates the manner and extent to which teachers in Taiwan deliver instruction designed to promote students' self-determination, and discusses the challenges we might face in this area. We hope that this preliminary investigation will create an empirical foundation for future research in order to support the design and development of evidence-based practices for use in self-determination instruction and curricula. Given their emphasis on the third wave of the disability movement (Wehmeyer, Bersani, \& Gagne, 2000), the development of self-advocacy and issues of self-determination have become increasingly important in educating students with disabilities. It is our hope that all students in Taiwan, including students with disabilities, will be able to become self-determined, and to make self-regulated choices and decisions relevant to their lives.

The present study provides an empirical documentation of teachers' implementation of self-determination instruction, but there are still some limitations to be addressed. First, the self-reported measurements using the Teaching Self-Determination Scale (TSDS) employed in this study might overlook the differences between teachers' perceptions of their implementation of instruction and the actual delivery of self-determination instruction. Second, this study did not include special education teachers from special schools, which might affect the feasibility of generalizing the results to self-determination practices for students with more severe and multiple disabilities. Finally, demographic variables affecting instructional efforts are not limited to gender, class setting, and teaching experience. A further limitation of this study that must be considered in interpreting the results is the interaction among the three variables, which might interactively affect the implementation of self-determination instruction. 
For future research, we suggest incorporating diverse and alternative methods to collect data on teachers' implementation of self-determination instruction, such as information from students or parents. In addition, future research could increase the sample size (e.g., by including special education teachers from special schools or high school teachers) in order to increase group diversity and representativeness, as well as to strengthen the understanding of self-determination practices across different educational levels and settings. From a larger sociological point of view, in addition to individual factors, a vast array of contextual variables, such as school policies, family support and upbringing, or students' motivation and intellectual abilities, could potentially influence teachers' implementation of self-determination instruction and should be further investigated. As to the educational implications for secondary and junior high school teachers, instructional activities and opportunities in developing self-regulated behaviors (e.g., decision and choice making, goal setting and attainment, and problem-solving skills) are essential for students with disabilities to be successful in schools and communities. In addition, the observed gender differences in instructional efforts might suggest that the school support system needs to address the fact that male teachers are disproportionally under-represented in primary and secondary schools in Taiwan, and to better support these teachers in providing self-determination instruction. Lastly, although teachers of self-contained classrooms showed high levels of implementation in the domain of Autonomy, skills relating to other aspects of self-determination need to be better incorporated into their daily instruction.

\section{Acknowledgments}

This study was supported by Investigation of Special Education Teachers' Self-Determination Instruction and Its Influence on the Academic Performance of Students with Disabilities Project from the Ministry of Science and Technology, Taiwan.

\section{References}

Agran, M., Cavin, M., Wehmeyer, M. L., \& Palmer, S. B. (2006). Participation of students with moderate to severe disabilities in the general curriculum: the effects of the self-determination learning model of instruction. Research and Practice for Persons with Severe Disabilities, 31, 230-241. https://doi.org/10.1177/ 154079690603100303

Burstein, K., Bryan, T., \& Chao, P. C. (2005). Promoting self-determination skills among youth with special health needs using participatory action research. Journal of Developmental and Physical Disabilities, 17, 185-201. https://doi.org/10.1007/s10882-005-3688-1

Carter, E. W., Lane, K. L., Pierson, M. R. \& Glaeser, B. (2006). Self-determination skills and opportunities of transition-age youth with emotional disturbance and learning disabilities. Exceptional Children, 72, 333-346. https://doi.org/10.1177/001440290607200305

Carter, E. W., Lane, K. L., Pierson, M. R. \& Stang, K. K. (2008). Promoting self-determination for transition-age youth: Views of high school general and special educators. Exceptional Children, 75, 55-70. https://doi.org/ $10.1177 / 001440290807500103$

Chambers, C. R., Wehmeyer, M. L., Saito, Y., Lida, K. M., Lee, Y., \& Singh, V. (2007). Self-determination: What do we know? Where do we go? Exceptionality, 15(1), 3-15. https://doi.org/10.1080/09362830709336922

Chao, P. C., \& Chou, Y. C. (2016, September). A National Survey of Elementary and Secondary Educators' Practice in Teaching Self-Determination: Lessons Learned from Taiwan. Paper presented at the International Symposium on Education and Social Sciences Conference, Singapore, Republic of Singapore.

Cho, H. J., Wehmeyer, M. L., \& Kingston, N. (2013). Factors that predict elementary educators' perceptions and practice in teaching self-determination. Psychology in the Schools, 50(8), 770-780. https://doi.org/ 10.1002/pits. 21707

Gaumer-Erickson, A. S., Noonan, P. M., Zheng, C., \& Brussow, J. A. (2014). The relationship between self-determination and academic achievement for adolescents with intellectual disabilities. Research in Developmental Disabilities, 36, 45-54. https://doi.org/10.1016/j.ridd.2014.09.008

Individuals with Disabilities Education Act, 20 U.S.C. $§ 1400$ (2004).

Jones, M. (2006). Teaching self-determination: Empowered teachers and empowered students. Teaching Exceptional Children, 39, 12-17. https://doi.org/10.1177/004005990603900102

Kelly, J. R., \& Shogren, K. A. (2014). The impact of teaching self-determination skills on the on-task and off-task behaviors of students with emotional and behavioral disorders. Journal of Emotional and Behavioral Disorders, 22(1), 27-40. https://doi.org/10.1177/1063426612470515 
Konrad, M., Fowler, C. H., Walker, A. R., Test, D. W., \& Wood, W. M. (2007). Effects of self-determination interventions on the academic skills of students with learning disabilities. Learning Disabilities Quarterly, 30, 89-113. https://doi.org/10.2307/30035545

No Child Left Behind Act of 2001, 20 U.S.C. § 6319. (2002).

Nota, L., Ferrari, L., Soresi, S., \& Wehmeyer, M. (2007). Self-determination, social abilities and the quality of life of people with intellectual disability. Journal of Intellectual Disability Research, 51, 850-865. https://doi.org /10.1111/j.1365-2788.2006.00939.x

Palmer, S. B., \& Wehmeyer, M. L. (2003). Promoting self-determination in early elementary school: Teaching self-regulated problem-solving and goal-setting skills. Remedial and Special Education, 24, 115-126. https://doi. org/10.1177/07419325030240020601

Powers, L. E., Ellison, R., Matuszewski, J., Wilson, R., Phillips, A., \& Rein, C. (2001). A multicomponent intervention to promote adolescent self-determination. Journal of Rehabilitation, 67, 13-19.

The Special Education Act, R.O.C. (2014).

Thoma, C. A., Nathanson, R., Baker, S. R., \& Tamura, R. (2002). Self-determination: What do special educators know and where do they learn it? Remedial and Special Education, 23, 42-47. https://doi.org/10.1177/07419325020230040701

Tung, C. H., \& Lin, H. C. (2005). The study of senior high school teachers' capacity on self-determination of students with mental retardation in special education schools. Journal of Special Education (Taiwan), 22, 145-178.

Wagner, M., Newman, L., Cameto, R., Garza, N., \& Levine, P. (2005). After high school: A first look at the post-school experiences of youth with disabilities. A report from the National Longitudinal Transition Study-2 (NLTS2). Retrieved from http://www.nlts2.org/reports/2005_04/nlts2_report_2005_04_complete. pdf

Walker, H. M., Calkins, C. F., Wehmeyer, M., Walker, L., Bacon, A., Palmer, S., . . Johnson, D. (2011). A social-ecological approach to Promote self-determination. UCEDD: A National Gateway to Self-Determination. https://doi.org/10.1080/09362835.2011.537220

Wehmeyer, M. L. (1999). A functional model of self-determination: Describing development and implementing instruction. Focus on Autism and Other Developmental Disabilities, 14, 53-61. https://doi.org/10.1177/10883576990140010

Wehmeyer, M. L., Agran, M., \& Hughes, C. (2000). A national survey of teachers' promotion of self-determination and student-directed learning. Journal of Special Education, 34(2), 58-68. https://doi.org/10.1177/ 002246690003400201

Wehmeyer, M. L., Bersani, H., \& Gagne, R. (2000). Riding the third wave: Self- determination and self-advocacy in the 21st century. Focus on Autism and Other Developmental Disabilities, 15, 106-115. https://doi.org/ 10.1177/108835760001500206

Wehmeyer, M. L., Palmer, S. B., Soukup, J. H., Garner, N. W., \& Lawrence, M. (2007). Self-determination and student transition planning knowledge and skills: Predicting involvement. Exceptionality, 15, 31-44. https://doi.org/10.1080/09362830709336924

\section{Copyrights}

Copyright for this article is retained by the author(s), with first publication rights granted to the journal.

This is an open-access article distributed under the terms and conditions of the Creative Commons Attribution license (http://creativecommons.org/licenses/by/4.0/). 